\title{
Correction to: Normalization and weighting: the open challenge in LCA
}

\author{
Andreas Roesch ${ }^{1} \cdot$ Serenella Sala ${ }^{2} \cdot$ Niels Jungbluth $^{3}$
}

Published online: 19 January 2021

๑) Springer-Verlag GmbH Germany, part of Springer Nature 2021

\section{Correction to: The International Journal of Life Cycle Assessment (2020) 25:1859-1865}

https://doi.org/10.1007/s1 1367-020-01790-0

The original version of this article, published on 9 July 2020 contained a mistake.

Unfortunately the first and last names of 2 authors were mixed up. Here are the correct names:

Andreas Roesch, Serenella Sala, Niels Jungbluth

The original article can be found online at https://doi.org/10.1007/ s11367-020-01790-0

Andreas Roesch andreas.roesch@agroscope.admin.ch

1 Agroscope, Reckenholzstrasse 191, 8046 Zurich, Switzerland

2 European Commission—Joint Research Centre, Via Enrico Fermi 2749, 21027 Ispra, VA, Italy

3 ESU-services Ltd., Vorstadt 14, 8200 Schaffhausen, Switzerland 